\title{
AN ONLINE STRAIGHTNESS DEVIATION MEASUREMENT METHOD OF ROTARY KILN CYLINDER
}

\author{
Kai Zheng, Yun Zhang, Lei Liu, Chen Zhao
}

Original scientific paper

The straightness deviation is a key parameter to evaluate the operation state of large low-speed rotary kiln in hot state. In order to measure the straightness deviation of the kiln cylinder, a method was presented and experimentally demonstrated in real industry field in this paper. Firstly, a reference coordinate system was established on the basis of the operation principle of rotary kiln. Based on the coordinate system, the cylinder of the rotary kiln was divided into several cross sections. The geometry data of each section was collected by the designed laser system. Considering that the data contain the components of straightness deviation and kiln cylinder surface deformation, a mathematical model was proposed to process the collected data. Furthermore, a three dimensional geometry model of the kiln cylinder was set up by employing the cloud data, which can be used to provide theoretical guidance to analyse the operation state of the rotary kiln. Finally, several experiments were conducted in real industry fields to verify the proposed method, and experimental results demonstrated that the method is effective to evaluate the straightness deviation of the rotary kiln. Moreover, the measurement system is featured with small measuring error and low cost.

Keywords: large rotary kiln; straightness deviation measurement; three dimensional geometry model

\section{Metoda računalnog mjerenja odstupanja ravnosti cilindra rotacijske peći}

Izvorni znanstveni članak

Odstupanje ravnosti predstavlja ključni parameter u procjeni operativnog stanja velike sporohodne rotacijske peći u toplom stanju. U svrhu mjerenja odstupanja ravnosti cilindra, u radu se predstavlja i eksperimentalno demonstrira metoda iz stvarnog industrijskog područja. Najprije je uspostavljen referentni koordinatni sustav zasnovan na principu rada rotacijske peći. Na temelju koordinatnog sustava, napravljeno je nekoliko poprečnih presjeka cilindra rotacijske peći. Geometrijski podaci svakog presjeka dobiveni su pomoću konstruiranog laserskog sustava. Uzimajući u obzir da podaci sadrže komponente pdstupanja ravnosti i deformacije površine cilindra peći, predložen je matematički model za obradu prikupljenih podataka. Nadalje, pomoću podataka iz oblaka postavljen je trodimenzionalni geometrijski model cilindra peći koji može pomoći u teorijskoj analizi radnog stanja rotacijske peći. Konačno, provedeno je nekoliko eksperimenata u stvarnom industrijskom području u svrhu provjere predložene metode i rezultati su pokazali da je metoda učinkovita u procjeni odstupanja ravnosti rotacijske peći. Uz to, taj sustav mjerenja karakterizira mala mjerna greška i niska cijena

Ključne riječi: velika rotacijska peć; mjerenje odstupanja ravnosti; trodimenzionalni geometrijski model

\section{Introduction}

Rotary kiln is large critical mechanical equipment with heavy load and low speed $(2 \div 6 \mathrm{rpm})$ in production of cement, metallurgical and chemical industry as well as environmental protection [1]. It is mainly composed of cylinder, riding rings, rollers and piers $[2,3]$, as shown in Fig. 1. It is extremely important in industry to maintain the reliability of the rotary kiln in order to ensure its 24hour continuous operation throughout the year [3, 4]. Therefore, monitoring the operation condition and determining its health state is of vital importance.

The straightness deviation is a vital parameter to determine mechanical state of a rotary machine in hot state $[5 \div 9]$. In cement rotary kiln, the six supporting rollers must support load of up to $15000 \div 20000 \mathrm{kN}[10$, 11]. It is reported that when the straightness deviation is $\pm 10 \mathrm{~mm}$, the body stress increases three times, and the load applied on the supporting roller increases one time

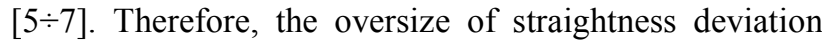
will cause the overload of supporting rollers, thereby leading to the overload of bearings (most are plain bearings) in them. When the plain bearings are overloaded, this will decrease thickness of the oil film [10]. In such cases, the heat is generated by friction and mechanical interaction of the roughness of the harder surface with the softer plain metal, leading to the malfunction of the kiln [11]. In extreme cases, it even ruptures the rotary kiln shell, leading to the serious economic losses $[12 \div 15]$. Therefore, the straightness deviation of the kiln cylinder can reflect the load of the roller bearing. Furthermore, it can be used to evaluate the operation state of the kiln and adjust the rotary kiln's axis to maintain the safety of the rotary kiln and reduce economic losses. It is impending to find an effective method to measure the straightness deviation of the kiln cylinder.

In order to measure the straightness deviation of the kiln cylinder in hot state, it is important to design a measuring instrument which features with easy operation, low cost and high accuracy as the whole measurement process is in abominably industrial environment. Also, as the data collected by the measurement system contain the two components of straightness deviation and kiln cylinder surface deformation, a mathematical model should be proposed to separate these two factors. Furthermore, considering the needs for analysing the overall operation state of the rotary kiln, the 3D geometry of the kiln cylinder should be established. Xiao et al. have studied the relationship between the straightness deviation of kiln and the stress cylinder surface [6]; Dhillon, B. S et al. had researched the fatigue life prediction of kiln roller under axis line deflection [7]; Pazand $\mathrm{K}$ et al had discussed the relationship between the shell deflects and Von-Mises equivalent stress on the inner surface of the rotary kiln [8]; but they did not propose any method for measuring the straightness deviation of kiln cylinder. Eng. Zbignie et al. have studied the causes of straightness deviation and kiln cylinder surface deformation and proposed a method for measuring them. However, no research has been presented to extract the information of straightness deviation of the collected data $[12,13]$. 
Weifei, Zheng et al. have put forward a method to measure the distortion of cement kiln axis, but they did not propose the mathematical method to calculate the straightness deviation $[14,15]$. Stutz et al. have presented a measurement system for straightness deviation of the kiln cylinder based on three dimensional laser scanning technology. The straightness deviation and the kiln cylinder surface deformation can be achieved by this system [16]. However, the application of the measuring system is limited as it is expensive and the cost of measurement process is high.

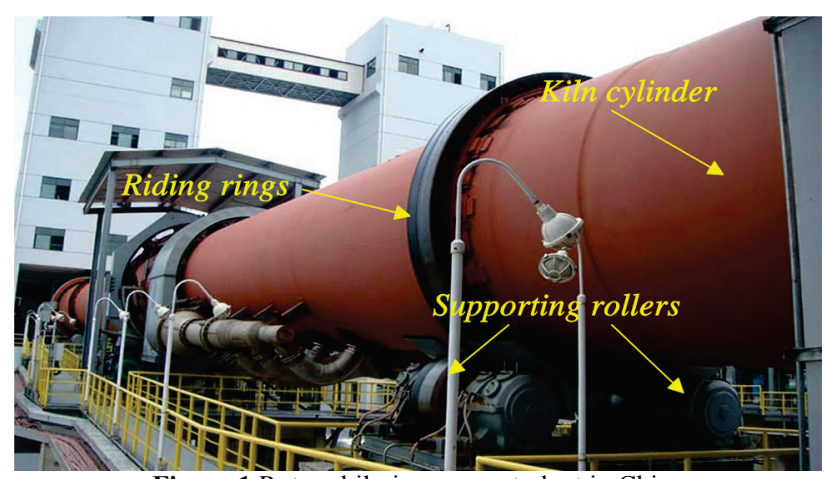

Figure 1 Rotary kiln in a cement plant in China

In this paper, a low-cost online method is proposed to obtain the straightness deviation of rotary kiln cylinder and the three dimensional geometry model of the rotary kiln cylinder in hot state. The remainder of this paper is organized as follows. In Part 2, the measurement principle and measurement system were introduced. In Part 3, a straightness deviation calculation model to process the sequence of measurements was proposed. In Part 4, a three dimensional geometry model of rotary kiln cylinder was presented. In Part 5, experiments were done to verify the designed system and the calculation method in real industry field and in Part 6, conclusions were drawn.

\section{Measurement method and measurement system \\ 2.1 Measurement method}

As shown in Fig. 2, the cylinder of the rotary kiln was comprised of many linked cross sections. The straightness deviation as well as the three dimensional geometry model of the rotary kiln cylinder can be obtained by measuring the geometry profile of each cross section with the laser system.

Before data acquisition, we first established a baseline at one side of the rotary kiln and supposed that the baseline is parallel to $X$ axis, which was perpendicular to $Y$ axis in the horizontal level and $Z$ axis in the vertical level (Fig. 3). The position coordinates of the instrument can be measured via the total station at the baseline. The measured coordinates are recorded as $x=\left[x_{1}, x_{2}, x_{3}, \ldots, x_{n}\right]$

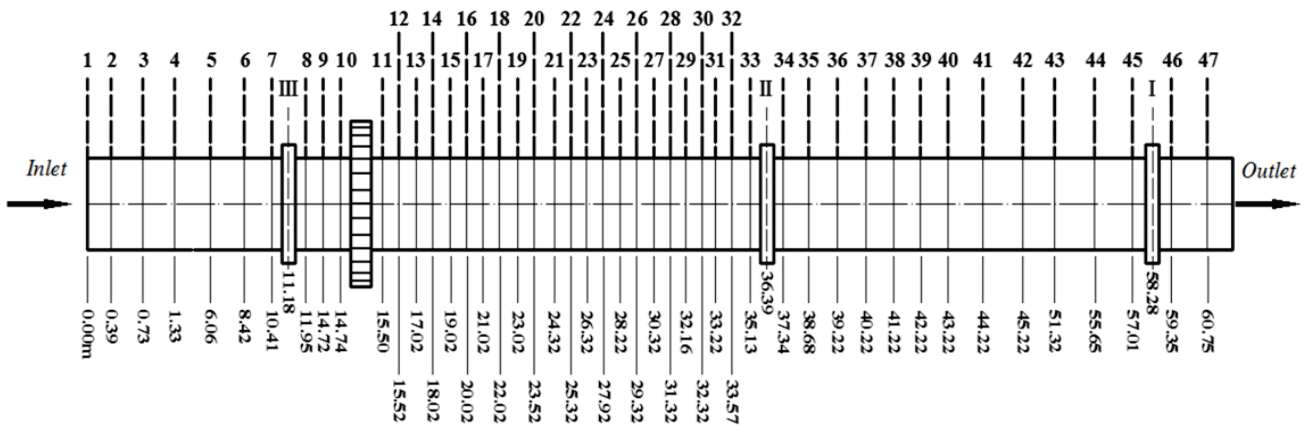

Figure 2 The diagram of measurement principle

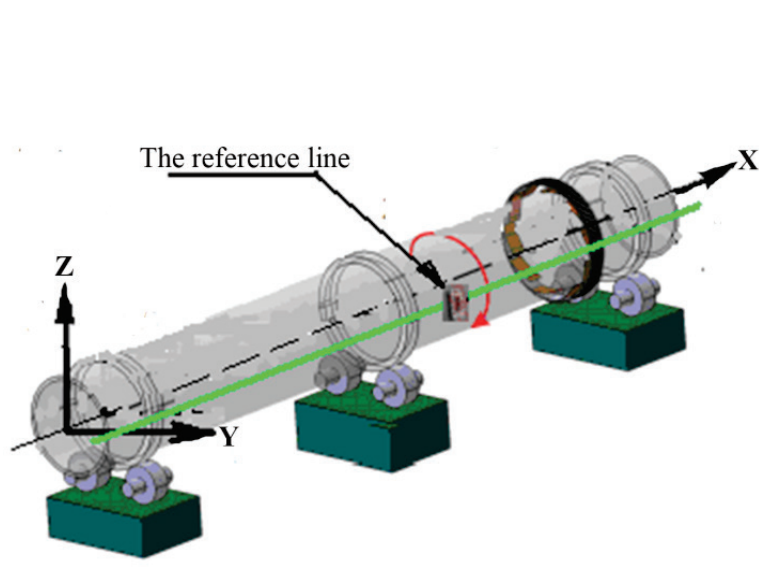

(a)

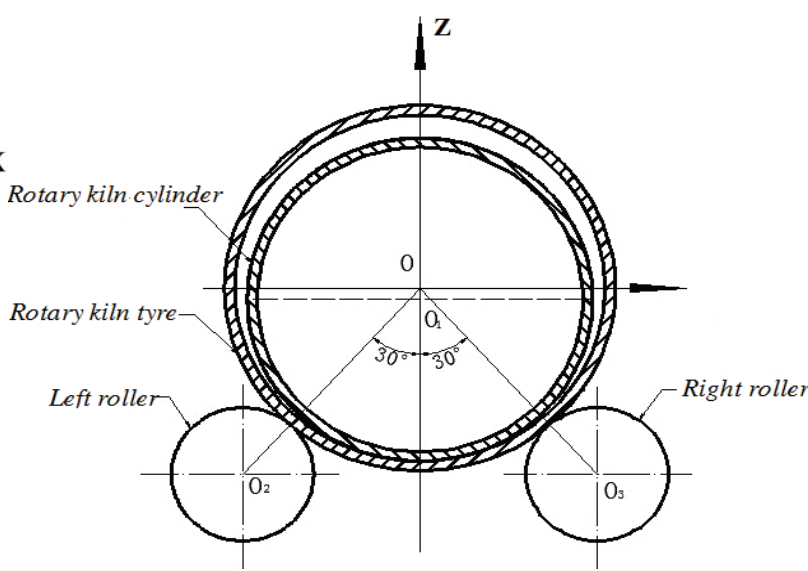

(b)

Figure 3 The coordinate system (a) The reference line of the start measuring point (b) The reference coordinate system

A number of cross sections for measurement were chosen on the basis of the length of the rotary kiln. For example, at least 30 cross sections should be selected for a rotary kiln with the length of $70 \mathrm{~m}$. Before measuring, the starting measurement point of each cross section on the cylinder of the kiln should be in the same reference line, as shown in Fig. 3a. During the actual measurement, the manhole of each cross section was used as the 
reference point. Under the influence of multiple factors such as temperature and gravity, the sections of the cylinder are generally not rounded and have straightness deviation and deformation. Fig. 4a is a schematic diagram of measuring the section deformation of the rotary cylinder with the measurement system. When the kiln cylinder rotated, the measuring spots $i(i=1,2,3, \ldots, n)$ on the cross section of the kiln cylinder moved in a circle with the rotation centre. And circles with different radiuses can be obtained when the cylinder rotated once. As a result, different distances $L_{i}$ between the instrument and various spots $i$ on the cross sections can be acquired by the measurement system. And the azimuth of the spots $i$ can be expressed by $\theta_{i}$, where $\theta_{i}=2 \pi /(n \cdot i)$.

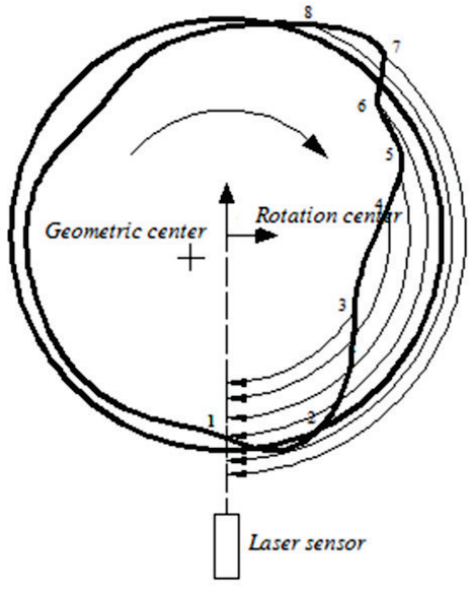

(a)

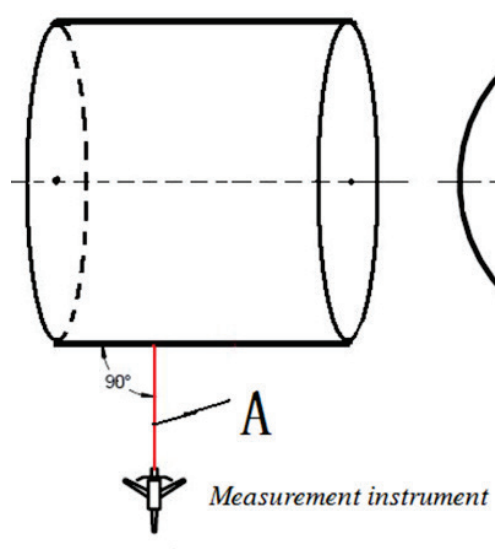

(b)

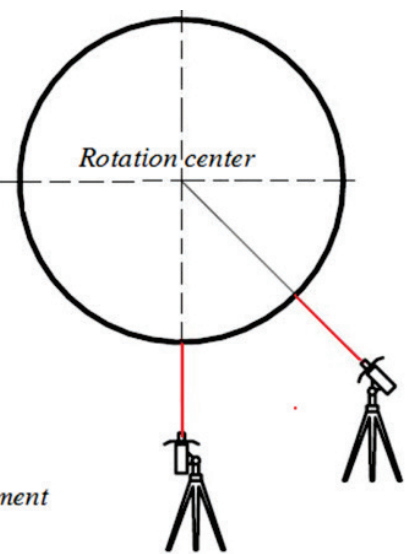

Figure 4 Diagram of the measurement principle: (a) Schematic diagram of measuring the section deformation of the rotating cylinder based on laser scanning (b) Schematic diagram of installing the measurement instrument

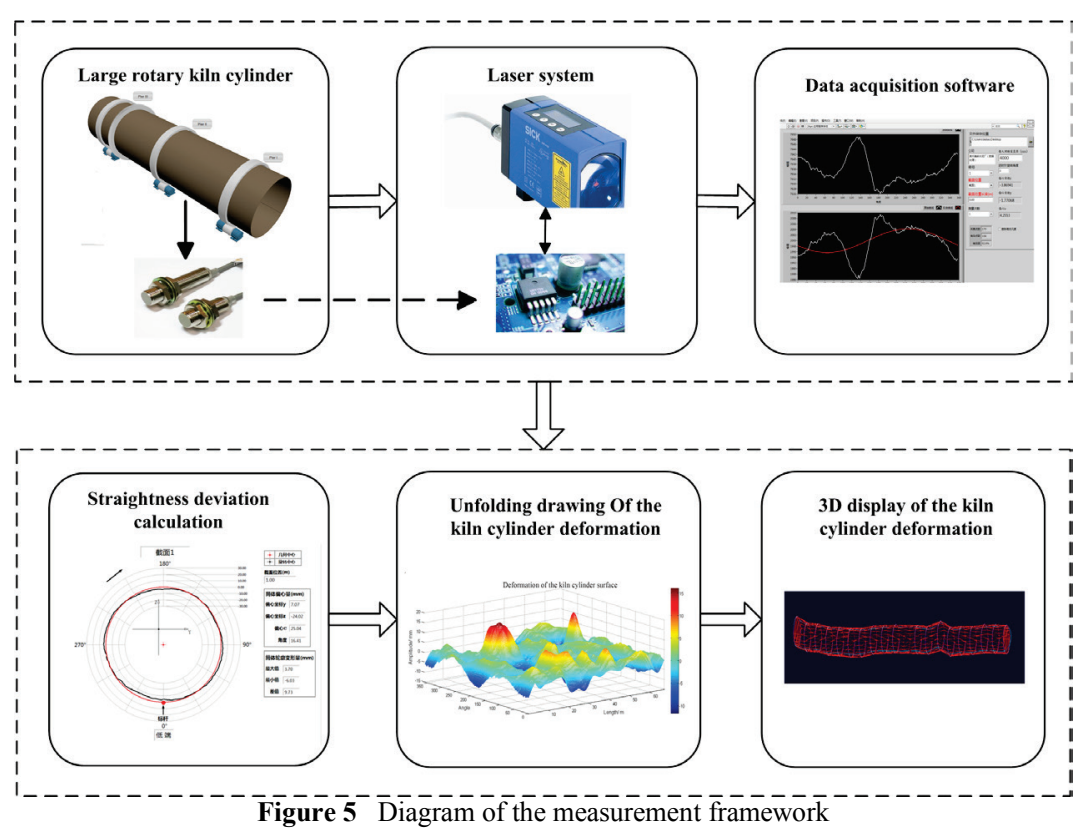

Specifically, $n$ is the number of sample points collected by the laser system, which can be calculated by the formula $n=f \cdot t$, where $f$ is the sample frequency and $t$ is sample time. And, the geometric centre and the eccentricity of each section can be calculated according to the established coordinate system and the mathematics model. Furthermore, the three dimensional geometry model of the rotary kiln can be obtained with the cloud data collected by the system.

\subsection{Measuring system}

As shown in Fig. 5, the straightness deviation measurement system for rotary kiln is composed of two parts: (i) data collection, which is responsible for the control of the laser system and data acquisition and storage (ii) model building, which is used for straightness deviation calculation and 3D geometry model building. The system mainly accomplishes the following tasks: (1) control of the laser for data collection; (2) data storage and model calculation.

The measurement system worked as follows in the real measurement in industry field. Before the measurement, a magnet was mounted on the meshing gear of the kiln, and a hall sensor was installed by the fixture. The hall sensor generated a pulse signal when it was opposite to the magnet. Then, the pulse signal was sent to the laser trigger control circuit by wireless module to control the start and stop the laser data acquisition system. Thereby, the amount of data collected would be 
controlled precisely in a cycle of the rotary kiln cylinder. The system interacted with the upper computer through serial port protocol (RS-232).

In this paper, the function of the system software could be summarized as follows: (1) Trigger the system to start and stop and collect data. (2) Calculate the straightness deviation and the three dimensional geometry models by mathematical model.

\section{Processing the sequence of measurements 3.1 The definition of eccentricity of the section}

In practical measurement, the laser sensor was aimed at the centre of the cylinder's section and detected the distance between the sensor and the cylinder surface in one revolution of kiln (about $15 \mathrm{~s}$ ). The data measured by the laser sensor was a simple sine wave without any local deformation on rotary cylinder. The relationship between the measured displacement data and rotation angle of the kiln can be expressed by Eq. (1).

$$
L(\theta)=e \cdot \cos \left(\frac{\theta}{180 \cdot \pi+\varphi}\right),
$$

Specifically, $e$ is the eccentricity of the cylinder's section, $\varphi$ is the measurement angle of the laser sensor, and $\theta(0 \leq \theta \leq 360)$ is the rotation angle. Schematically, this situation is shown in Fig. 6a and the simulated result is shown in Fig. 6b. Then, the eccentricity of the cylinder's section can be described by the following Eq. (2):

$$
e=\frac{P_{\max }-P_{\min }}{2} .
$$

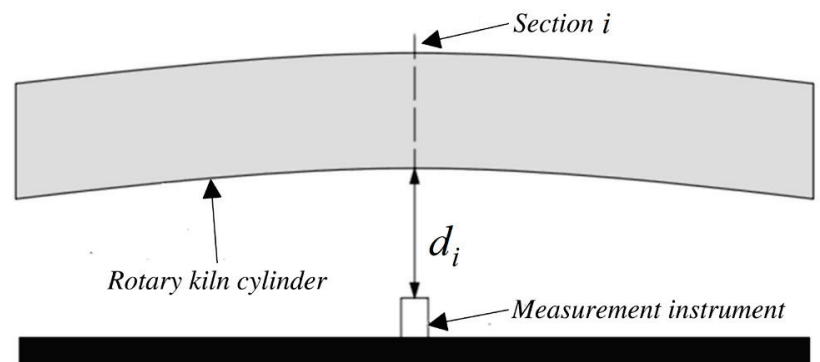

(a)

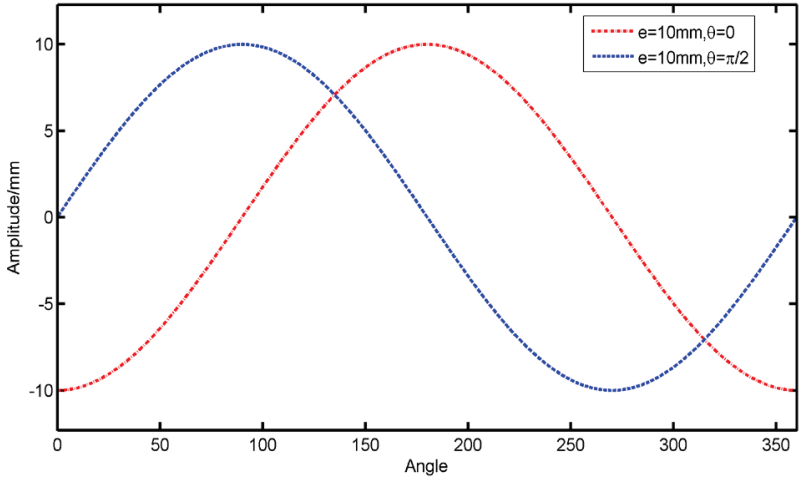

(b)

Figure 6 The simulation result when there is only straightness deviation of rotary kiln cylinder: (a) The diagram of Laser sensor installation (b) The simulation result
In the operation of the rotary kiln, the form of the cylinder's deformation became complicated because of uneven temperature distribution and thermal expansion around the rotary cylinder. In section measurement, the actually measured data consisted of rotary kiln's straightness deviation and cylinder surface deformation. Therefore, it is essential to adopt a reasonable mathematical model to separate measured data in the calculation of rotary kiln's straightness deviation.

According to the operation principle of the rotary kiln, before calculating the rotary kiln's straightness deviation and building the three-dimensional model of rotary kiln, we put forward three definitions as follows:

- The rotation axis of the kiln is a straight line, and the measured axis of the kiln refers to the curve connected by all the geometric centres of the measured sections.

- The rotation centre is surrounded by the geometric centre of the section while the rotary kiln rotates and the movement trail of the geometric centre is a circle, whose radius is equivalent to the eccentricity of the section.

- The coordinate of eccentricity of the section is the measured result when the rotary kiln rotates at a certain place; that is to say, the calculation of the coordinate of eccentricity is based on the reference point.

\subsection{The calculation model of straightness deviation}

In practical measurement, the cylinder was divided into $N$ sections $(N>20)$ along axis $X$, as mentioned in Section 2.1. Then, the cross sections of the kiln cylinder were measured one by one with the measurement system. According to the definitions mentioned in Section 3.1, the rotation straight line was surrounded by all the measured sections and the real axis of the rotary kiln was the curve formed by the geometric centres of all the sections. Hence, the key of the measurement problem of the straightness deviation of the rotary kiln is to calculate the geometric centres of the measured sections.

In order to calculate the coordinate of the geometric centre and the eccentricity of each section, we assume that the radial deviation is $\xi$ which represents the deviation value between contours and base circle, which value satisfies Eq. (3):

$\sum_{i=1}^{n} \xi_{i}=0, \sum_{i=1}^{n} \xi_{i}^{2}=\min$

As is shown in Fig. 6, it can be found that there was a base circle based on an average circle of each cross section. By using this method, the centre coordinate of the base circle can be calculated by utilizing the collected data and then the eccentricity can be obtained.

Detailed process of the model is described in Fig. 7. The parameters are defined as follows: $O$ is the rotation centre of the section; $O^{\prime}$ is the geometric centre of each cross section of the kiln cylinder while $(a, b)$ is its coordinate; $L_{i}\left(x_{i}, y_{i}\right)$ is the coordinate of the measured points $(i=1,2,3, \ldots, n) ; n$ is the number of the sampled points by the laser system; $R$ is the radius of the base circle; $r_{i}$ is the radius from point $L_{i}$ to rotation centre of 
the section; and the eccentricity can be expressed by Eq. (4)

$$
e=\sqrt{a^{2}+b^{2}}
$$

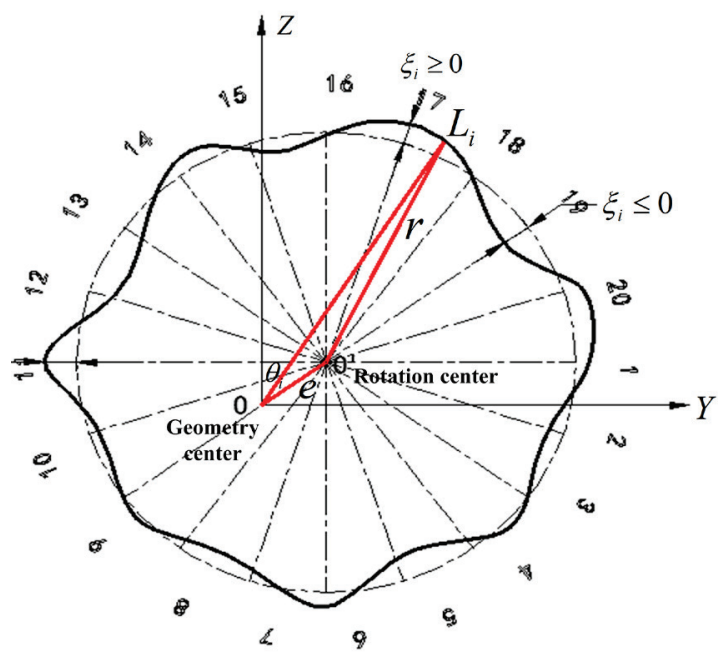

Figure 7 The geometrical model of the calculation method

By geometrical analysis $[17 \div 22]$ of $\Delta L_{i} O O^{\prime}$, we can get:

$$
r_{i}=e \cdot \cos \left(\theta_{i}-\varphi\right)+\sqrt{\left(R+\xi_{i}\right)^{2}-\left[e \cdot \sin \left(\theta_{i}-\varphi\right)\right]^{2}} .
$$

As $e<<R, \quad \sin \left(\theta_{i}-\varphi\right) \leq 1$.

And $a=e \cdot \cos \varphi, b=e \cdot \sin \varphi$, the above equation can be converted to Eq. (7)

$\xi_{i}=r_{i}-R-a \cdot \cos \theta_{i}-b \cdot \sin \theta_{i}$.

where $\xi_{i}$ is the radial distance from point $L_{i}\left(x_{i}, y_{i}\right)$ to the basic circle.

$\sum_{i=1}^{n} \xi_{i}^{2}$ is the minimum, and $\sum_{i=1}^{n} \xi_{i}=0$. That is:

$\sum_{i=1}^{n}\left(r_{i}-R-a \cdot \cos \theta_{i}-b \cdot \sin \theta_{i}\right)=0$

$\min _{a=\{R, a, b\}} J(\alpha)=\sum_{i=1}^{n}\left[r_{i}-R-a \cdot \cos \theta_{i}-b \cdot \sin \theta_{i}\right]^{2}$

If $\partial \min _{\alpha=\{R, a, b\}} J(\alpha) / \partial a=0, \partial \min _{\alpha=\{R, a, b\}} J(\alpha) / \partial b=0$

It can be got:

$$
\begin{aligned}
& R=(1 / n) \sum_{i=1}^{n} r_{i} \\
& a=(2 / n) \sum_{i=1}^{n} r_{i} \cos \theta_{i} \\
& b=(2 / n) \sum_{i=1}^{n} r_{i} \sin \theta_{i}
\end{aligned}
$$

It is difficult to calculate the geometric centre and the eccentricity of each cross section by Eqs. (11) and (12) as the radius $r_{i}$ of each cross section is a variable. And the laser sensor can only measure the deviation value of radius of each section, but cannot measure the dynamic radius. It needs to transform Eqs. (11) and (12) in order to calculate them.

The radius of the cross section can be express by $r_{i}=R_{c}+\Delta r_{i}$, where $R_{c}$ is the mean radius, and for each section, it can be deemed to a constant; $\Delta r_{i}$ is the deviation value of radius of each section which can be measured by the laser system. Therefore, Eqs. (11) and (12) can be transformed to Eqs. (13) and (14) respectively.

$$
\begin{aligned}
& a=(2 / n) \sum_{i=1}^{n} \Delta r_{i} \cos \theta_{i}+(2 / n) \sum_{i=1}^{n} R_{c} \cos \theta_{i} \\
& b=(2 / n) \sum_{i=1}^{n} \Delta r_{i} \sin \theta_{i}+(2 / n) \sum_{i=1}^{n} R_{c} \sin \theta_{i}
\end{aligned}
$$

And as:

$$
\begin{aligned}
& (2 / n) \sum_{i=1}^{n} R_{c} \sin \theta_{i}=0 \\
& (2 / n) \sum_{i=1}^{n} R_{c} \cos \theta_{i}=0
\end{aligned}
$$

Therefore, Eqs. (13) and (14) can be transformed to Eqs. (17) and (18) respectively:

$$
\begin{aligned}
& R=(1 / n) \sum_{i=1}^{n} r_{i} \\
& a=(2 / n) \sum_{i=1}^{n} \Delta r_{i} \cos \theta_{i}, b=(2 / n) \sum_{i=1}^{n} \Delta r_{i} \sin \theta_{i}
\end{aligned}
$$

Therefore, the geometric centre $(a, b)$, base circle $R$ and eccentricity can be calculated using the above Eqs. (17) and (18).

\section{Three dimensional geometry model}

In order to establish the three dimensional geometry model of the rotary kiln cylinder, a mathematical model was proposed. We set $N$ as the number of displacements recorded by the laser sensor, $n$ as the number of sections selected, $R$ as the radius of the rotary kiln, and $L_{i j}(1 \leq i \leq n, 1 \leq j \leq N)$ as the displacement value measured by the laser sensor (Fig. 8). Based on the established spatial coordinate system, the displacement data acquired by the laser sensor could be converted into spatial values. The spatial point coordinates of each section can be expressed with a matrix. Where the spatial point coordinates of the section can be expressed with the matrix $\boldsymbol{M}_{i}$.

$$
\boldsymbol{M}_{i}=\left[\begin{array}{ccc}
x_{i} & \sin \beta_{1} R_{1} & \cos \beta_{1} R_{1} \\
x_{i} & \sin \beta_{2} R_{2} & \cos \beta_{2} R_{2} \\
x_{i} & \ldots & \ldots \\
x_{i} & \sin \beta_{k} R_{k} & \cos \beta_{k} R_{k} \\
x_{i} & \ldots & \ldots \\
x_{i} & \sin \beta_{N} R_{N} & \cos \beta_{N} R_{N}
\end{array}\right]_{N^{*} 3}
$$

Where $\beta_{k}=2 \pi k / N, 1 \leq i \leq n, 1 \leq j \leq N$ 


$$
R_{i}=L_{i}-\sum_{i=1}^{N} L_{i} / N+R_{c}
$$

$\boldsymbol{M}_{i}$ is the matrix of spatial coordinate point converted from the collected data by the laser system. It contains the two components of straightness deviation and cylinder surface deformation. In order to establish the three dimensional geometry model of rotary kiln, it is necessary to transform the matrix $\boldsymbol{M}_{i}$ to the $\boldsymbol{M}_{i}{ }^{\prime}$ by the calculation method mentioned above in Section 3.2 where $\boldsymbol{M}_{i}{ }^{\prime}$ is the corresponding matrix formulation.

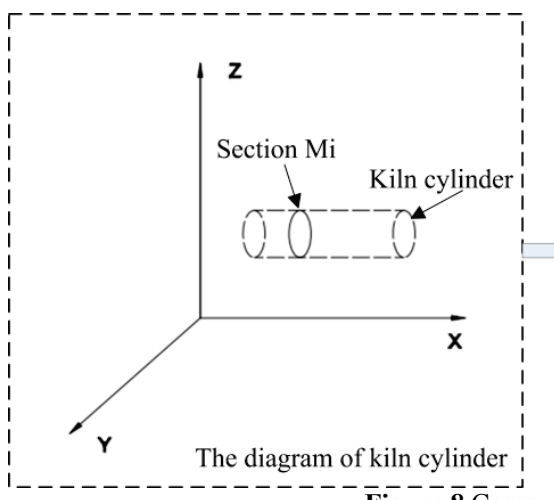

$\overline{\text { Figure }} \mathbf{8} \overline{\mathrm{C}}$ omputation process diagram

As the data acquired were distributed in scattered points, an interpolation method could be used for interpolation calculation for them. There are many interpolation methods such as nearest neighbour interpolation, bilinear interpolation and cubic interpolation. Cubic interpolation produces more accurate results than nearest neighbour Interpolation and bilinear interpolation, but 70-time multiplications and 45-time additions are needed for interpolation calculation of each point. Therefore, it needs far larger amount of calculation than nearest neighbour interpolation and Bilinear Interpolation. As the amount of the data acquired concerning the rotary kiln is not large, cubic interpolation $[23 \div 25]$ can be adopted. Considering that the Delaunay triangle $[26 \div 28]$ has demonstrated some excellent characteristics such as missing and spurious keypoint influence the Delaunay triangulation net only locally, in this paper, the Delaunay triangulation method was used to triangulate the scattered data points to form the three dimensional geometry model of the rotary kiln cylinder.

According to cubic interpolation, the value of the point to be interpolated was known based on interpolation of the $4 \times 4$ points around it. The formula is set out as

$z^{\prime}\left(x^{\prime}, y^{\prime}\right)=\sum_{i=0}^{3} \sum_{j=0}^{3} a_{i j} x^{i} y^{j}$

where $x^{\prime}, y^{\prime}, z^{\prime}$ represent the spatial data. The procedures for calculating the coefficient $a_{i j}$ depend on the features of the interpolation data. $i$ and $j$ are local coordinates of the 16 points around the point to be interpolated. Through cubic interpolation, the coordinates of the point to be interpolated were converted into floating point coordinates $(i+u, j+v)$. Based on the coordinates of 16 points around it, the target coordinate value $f(i+u, j+v)$ can be known via the following interpolation Eq. (17):

$f(i+u, j+v)=\boldsymbol{A B C}$

where $\boldsymbol{A}, \boldsymbol{B}$ and $\boldsymbol{C}$ are all matrixes, with their forms set out as:

$$
\begin{aligned}
\boldsymbol{A} & =\left[\begin{array}{llll}
s(1+u) & s(u) & s(1-u) & s(2-u)
\end{array}\right] \\
\boldsymbol{B} & =\left[\begin{array}{cccc}
f(i-1, j-2) & f(i, j-2) & f(i+1, j-2) & f(i+2, j-2) \\
f(i-1, j-1) & f(i, j-1) & f(i+1, j-1) & f(i+2, j-1) \\
f(i-1, j) & f(i, j) & f(i+1, j) & f(i+2, j) \\
f(i-1, j+1) & f(i, j+1) & f(i+1, j+1) & f(i+2, j+1)
\end{array}\right] \\
\boldsymbol{C} & =\left[\begin{array}{llll}
s(1+v) & s(v) & s(1-v) & s(2-v)
\end{array}\right]^{\mathrm{T}}
\end{aligned}
$$

Function $S$ in matrixes $\boldsymbol{A}$ and $\boldsymbol{C}$ is the interpolation basis function. The expression of the common basis function is:

$$
S(w)=\left\{\begin{array}{lr}
1-2|w|^{2}+|w|^{3}, & |w|<1 \\
1-8|w|+5|w|^{2}-|w|^{3}, & 1 \leq|w|<2 \\
0, & |w| \geq 2
\end{array}\right.
$$

The calculation procedures of Cubic Interpolation are set out as follows:

- Obtain the coordinates of the 16 points around the point to be interpolated and express them with Matrix $\boldsymbol{B}$;

- Based on Eq. (25), obtain the interpolation basis vectors $s(u)$ and $s(v)$ of the interpolation basis function $s(w)$ in $x$ axis and $y$ axis directions respectively and express them with matrixes $\boldsymbol{A}$ and $\boldsymbol{C}$;

- Calculate the value of the point to be interpolated based on Eq. (21). According to Delaunay triangulation and Cubic interpolation method, a three dimensional geometry model can be set up with the cloud data.

\section{Experiments and result 5.1 Verification of the system in industry field}

In order to verify the effectiveness of the measurement method, we did experiments in the real industry field. And all the eccentricities of the measured cross sections have been calculated. The results are shown in the following Fig. 9 and Fig. 10. 

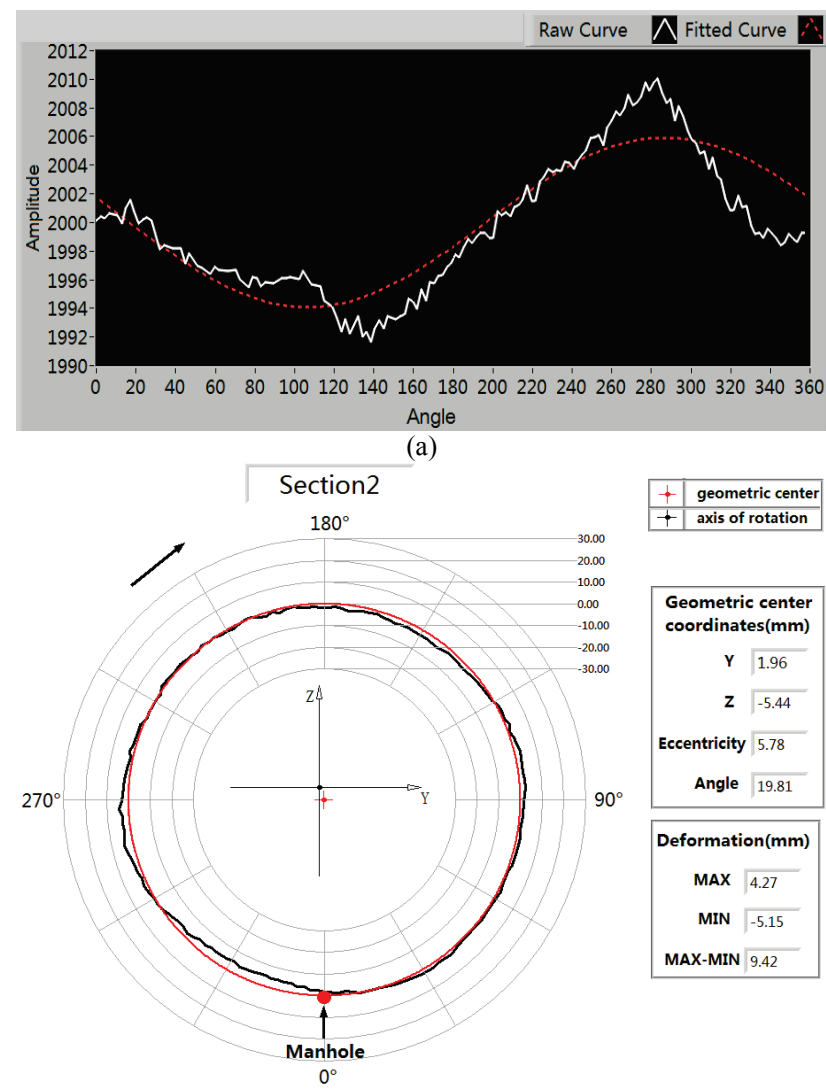

(b)

Figure 9 Measurement result for section 2\#: (a) The collected data and the fitted result; (b) The collected data and the fitted result in the system of polar coordinates and $e=28,16 \mathrm{~mm}$

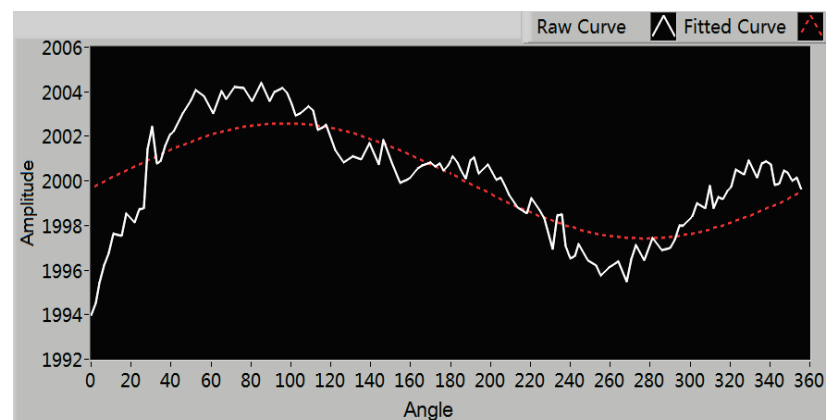

(a)

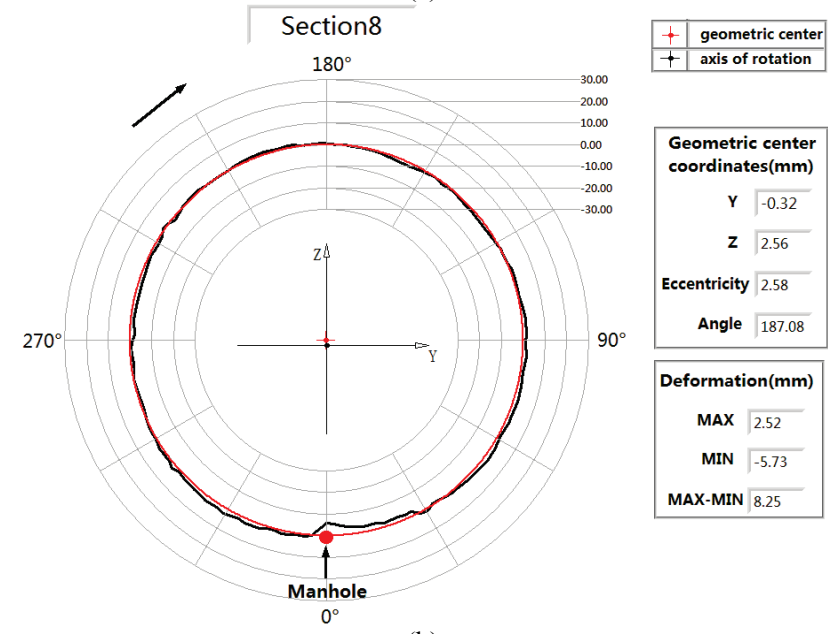

(b)

Figure 10 Measurement result for section 8\#: (a) The collected data and the fitted result; (b) The collected data and the fitted result in the system of polar coordinates and $e=2,58 \mathrm{~mm}$
After processing the collected data using the mathematical model, the raw curve was fitted to a sine curve, which matched the simulated result mentioned in Section 3.1. Also, it was proved that the measurement method was valid in the real industry field as we used this method to evaluate the rotary kiln's straightness deviation in at least three cement plants in China. Moreover, the changing trend of the cylinder's straightness deviation was obtained as shown in Fig. 11.

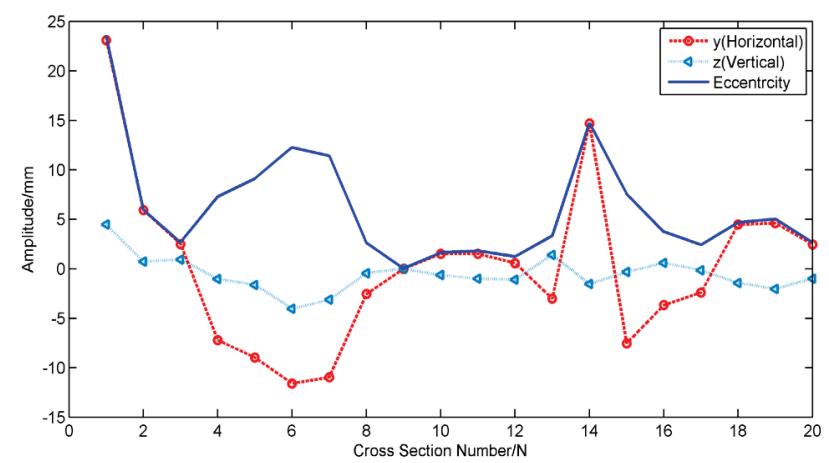

Figure 11 The diagram of the variation trend of the straightness deviation

\subsection{Experiments of errors of instalment}

In measurement, it is difficult to aim the laser sensor at the centres of the cylinder's section perfectly. Given the above situation, it is necessary to evaluate the influence of the instalment error. Two different situations were singled out. One was to assess the effect caused by the instalment error of laser sensor, and the results were shown in Fig. 12. Another aimed to assess the effect when the deviation angle of the laser beam is $5^{\circ}$ relative to perfect position, and the results were shown in Fig. 13.

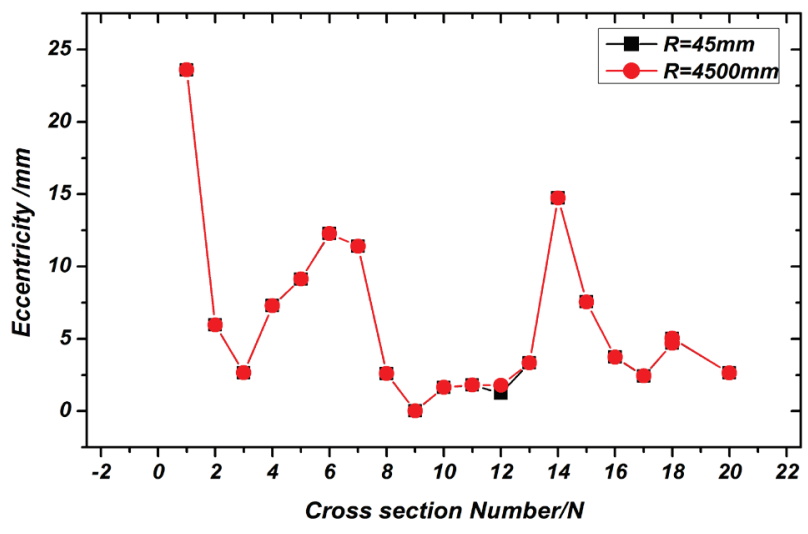

Figure 12 The influence of instalment laser in different distances. It can be found that there is almost no influence in different distances.

After detailed analysis of Fig. 12 and Fig. 13, it is clear that the calculation method can help compensate for the errors caused by instalment and angle deviation. It means that it is easy for the instalments of the measurement instrument by using this method to evaluate the straightness deviation of the rotary kiln cylinder. And it is convenient to obtain the change trend of it with this calculation method. 


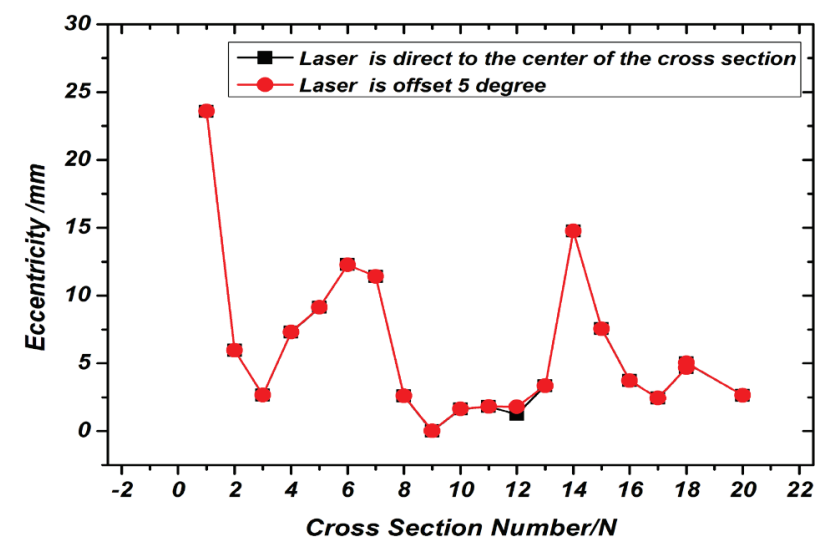

Figure 13 The influence of instalment laser in an offset angle $\left(\leq 5^{\circ}\right)$. It can be found that there is almost no influence in an offset angle $\left(\leq 5^{\circ}\right)$.

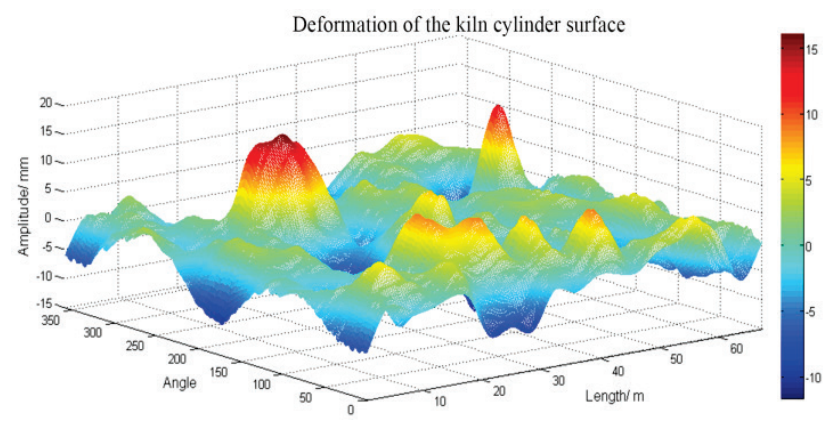

Figure 14 Deformation of the kiln cylinder surface

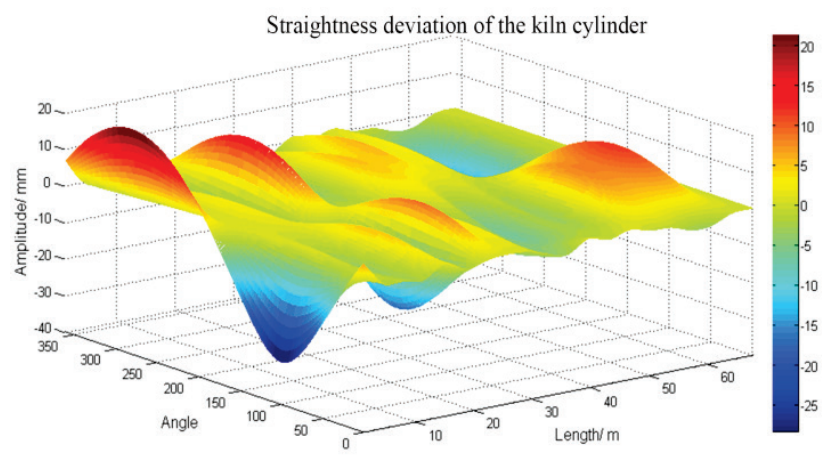

Figure 15 Straightness deviation of the kiln cylinder

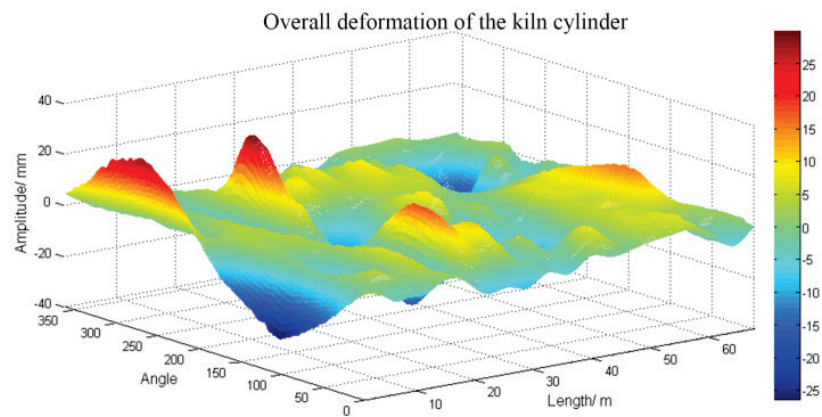

Figure 16 Overall deformation of the kiln cylinder (including straightness deviation and deformation of kiln cylinder surface)

\subsection{Results of three-dimensional model}

According to the three-dimensional model mentioned in Section 4, the measured data were analysed and

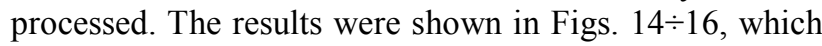
were three dimension drawings expanded along Axis $X$. The straightness deviation and deformation of the rotary cylinder surface can be observed directly in Figs. 14 $\div 17$. The three-dimensional model not only offered a theoretical basis to evaluate the operating conditions of rotary kiln, but also laid a solid foundation for the mechanical model analysis.

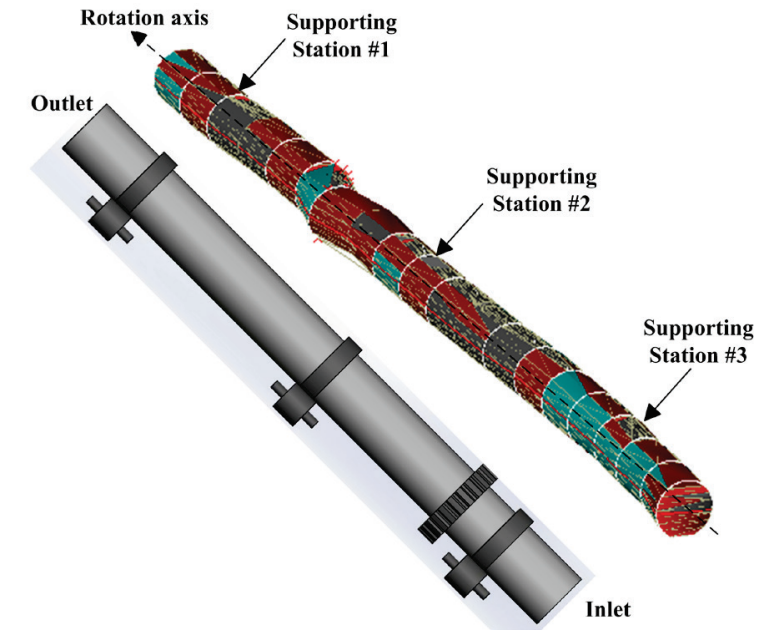

Figure 17 Three-dimensional geometry model of rotary kiln cylinder

\section{Conclusion}

At present, measuring the straightness deviation of large rotary kiln cylinder in hot state remains a challenge in cement industry. Therefore, a measurement method and instrument were proposed in this paper. Based on the established coordinate system, the cylinder of the rotary kiln was divided into several cross sections. And the geometry data of each section were collected by the designed system. A mathematical model was proposed to separate the factors of straightness deviation and cylinder deformation from the collected data. Moreover, a threedimensional geometry model was established based on the cloud data. Experiments on measurement of the straightness deviation of large rotary kiln in real industry field were conducted. The experimental results indicated that the proposed measurement system and method were effective for evaluating the straightness deviation of the kiln cylinder. It provides theoretical foundation for maintaining the rotary kiln.

The measurement method for the kiln cylinder can be applied in the cement, metallurgical and chemical plant, which has a wide application prospect. In the future, we will optimize the measurement method and the threedimensional model of the kiln cylinder, and research on the deformation mechanism of it.

\section{Acknowledgment}

This research is supported and funded by National centre for rotary kiln detection technology and Hubei Digital Manufacturing Key Laboratory. We also thank the anonymous reviewers and editors for their valuable comments and suggestions.

\section{References}

[1] Žiga, A.; Karač, A.; Vukojević, D. Analytical and numerical stress analysis of the rotary kiln ring. // Tehnički vjesnik. 20, 6(2013), pp. 941-946. 
[2] Goshayeshi, H. R.; Poor, F. K. Modeling of Rotary Kiln in Cement Industry. // Energy and Power Engineering. 8, 1(2016), pp. 23. https://doi.org/10.4236/epe.2016.81003

[3] Saidur, R. et al. A review on kiln system modeling. // Renewable and Sustainable Energy Reviews. 15, 5(2011), pp. 2487-2500. https://doi.org/10.1016/j.rser.2011.01.020

[4] Noshirvani, G.; Shirvani, M.; Askari-Mamani, J.; Nourzadeh, H. Estimation of coating thickness in a rotary kiln by using shell temperature and kiln modeling. // ZKG international. 11, (2013), pp. 58-71.

[5] Li, Xuejun; Yiping, Shen; Songlai, Wang. Dynamic modeling and analysis of the large-scale rotary machine with multi-supporting. // Shock and Vibration. 18, 12(2011), pp. 53-62. https://doi.org/10.1155/2011/541049

[6] Xiao, Yougang; Xuejun Li; Xiaoqing Chen. General solution to kiln support reactions and multi-objective fuzzy optimization of kiln axis alignment. // Structural and Multidisciplinary Optimization. 36, 3(2008), pp. 319-327. https://doi.org/10.1007/s00158-007-0164-9

[7] Dhillon, B. S. Multiaxial fatigue life prediction of kiln roller under axis line deflection. // Applied Mathematics and Mechanics. 31, 2(2010), pp. 205-214. https://doi.org/10.1007/s10483-010-0208-x

[8] Pazand, K.; Panahi, M. S.; Pourabdoli, M. Simulating the mechanical behavior of a rotary cement kiln using artificial neural networks. // Materials \& Design. 30, 9(2009), pp. 3468-3473. https://doi.org/10.1016/j.matdes.2009.03.016

[9] Ramanenka, D.; Stjernberg, J.; Jonsén, P. FEM investigation of global mechanisms affecting brick lining stability in a rotary kiln in cold state. // Engineering Failure Analysis. 59, (2016), pp. 554-569. https://doi.org/10.1016/j.engfailanal.2015.10.023

[10] Rusinski, E.; Stamboliska, Z.; Moczko, P. Proactive control system of condition of low-speed cement machinery. // Automation in Construction. 31, (2013), pp. 313-324. https://doi.org/10.1016/j.autcon.2012.12.001

[11] Stamboliska, Z.; Rusiński, E.; Moczko, P. Proactive Condition Monitoring of Low-Speed Machines. Springer International Publishing. (2015), pp. 53-68.

[12] Zbigniew, K. Geometry Measurement of Kiln Shell in Dynamic Conditions. // Cement \& Building Materials. 16, 6(2004)

[13] Zbigniew, K.; Geoserverex, P. Geometry Measurements of Kiln shell in Dynamic Conditions. // Cement \& Building Materials. (2004), pp. 34-37.

[14] Weifei, Zheng. Dynamical measure the distortion of cement kiln axis and kiln shell cylindrical deformation. Master's thesis. Wuhan University of Technology, 2011.

[15] Zhang, Y.; Weifei, Zheng. Dynamic detecting method of the axial distortion and shell distortion of rotary kiln. // Cement Engineering. (2011) 02, 023.

[16] Stutz, T. Method and device for detecting straightness deviations and/or deformations in a rotary kiln: U. S. // Patent Application 14/129,421[P]. 2012-6-15.

[17] Schalk, P.; Ofner, R.; O'Leary, P. Pipe eccentricity measurement using laser triangulation. // Image and Vision Computing. 25, 7(2007), pp. 1194-1203. https://doi.org/10.1016/j.imavis.2006.04.021

[18] Guo, Y.; Wang, Y.; Liu, X. Real-time optical detection system for monitoring roller condition with automatic error compensation. // Optics and Lasers in Engineering. 53, (2014), pp. 69-78. https://doi.org/10.1016/j.optlaseng.2013.08.007

[19] Sami, F. A.; Doiron, T.; Sahay, C. Uncertainty analysis of cylindricity measurements using bootstrap method. // Measurement. 42, 4(2009), pp. 524-531. https://doi.org/10.1016/j.measurement.2008.09.008

[20] Venkaiah, N.; Shunmugam, M. S. Evaluation of form data using computational geometric techniques-Part I:
Circularity error. // International Journal of Machine Tools and Manufacture. 47, 7(2007), pp. 1229-1236. https://doi.org/10.1016/j.jijmachtools.2006.08.010

[21] Liu, Dong et al. A robust circle detection algorithm based on top-down least-square fitting analysis. // Computers \& Electrical Engineering. 40, 4(2014), pp. 1415-1428. https://doi.org/10.1016/j.compeleceng.2014.03.011

[22] Kenichi, K.; Rangarajan, P. Hyper least squares fitting of circles and ellipses. // Computational Statistics \& Data Analysis. 55,6(2011), pp. 2197-2208. https://doi.org/10.1016/j.csda.2010.12.012

[23] Peng, Junzheng et al. Using triangle-based cubic interpolation in generation of object-adaptive fringe pattern. // Optics and Lasers in Engineering. 52, (2014), pp. 41-52. https://doi.org/10.1016/j.optlaseng.2013.05.014

[24] Yi, Longtao, et al. A new background subtraction method for energy dispersive X-ray fluorescence spectra using a cubic spline interpolation. // Nuclear Instruments and Methods in Physics Research Section A: Accelerators, Spectrometers, Detectors and Associated Equipment. 775, (2015), pp. 12-14. https://doi.org/10.1016/j.nima.2014.11.100

[25] Sidik, Nor Azwadi Che; Attarzadeh, Mohamad Reza Niaki. The use of cubic interpolation method for transient hydrodynamics of solid particles. // International Journal of Engineering Science. 51, (2012), pp. 90-103. https://doi.org/10.1016/j.ijengsci.2011.08.014

[26] Shewchuk, J. R. Triangle: Engineering a 2D quality mesh generator and Delaunay triangulator. // Applied computational geometry towards geometric engineering. Springer Berlin Heidelberg, 1996, pp. 203-222. https://doi.org/10.1007/BFb0014497

[27] Dou, Jianfang; Qin, Qin; Zimei, Tu. Improved SVD matching based on Delaunay triangulation and belief propagation. // Optik-International Journal for Light and Electron Optics. 126, 24(2015), pp. 4861-4867. https://doi.org/10.1016/j.ijleo.2015.09.195

[28] Shewchuk, J. R.; Brielin C. Brown. Fast segment insertion and incremental construction of constrained Delaunay triangulations. // Computational Geometry. 48, 8(2015), pp. 554-574. https://doi.org/10.1016/j.comgeo.2015.04.006

\section{Authors' addresses}

\section{Kai Zheng, PhD*}

Chongqing University of Posts and Telecommunications NO. 2, Chongwen Road, Nan'an District, Chongqing, China E-mail: zhengkai2001@163.com

* received PhD in Wuhan University of Technology in 2016.

\section{Yun Zhang, Professor}

Corresponding author

School of Mechanical and Electronic Engineering

Wuhan University of Technology

Luoshi Road 122, Hongshan District, Wuhan, China

E-mail:whkasco@aliyun.com

\section{Lei Liu, master student}

School of Mechanical and Electronic Engineering Wuhan University of Technology

Luoshi Road 122, Hongshan District, Wuhan, China E-mail: 260428845@qq.com

\section{Chen Zhao, master student}

School of Mechanical and Electronic Engineering Wuhan University of Technology Luoshi Road 122, Hongshan District, Wuhan, China E-mail: zhaochen@whut.edu.cn 